\title{
Life cycle inventory of the commercial production of compost from oil palm biomass: a case study
}

\begin{abstract}
This paper compared the life cycle inventory (LCI) obtained from three commercial oil palm biomass composting projects in Malaysia which use the open windrow composting system. The LCI was obtained and calculated based on the functional unit of $1 \mathrm{t}$ of compost produced. The input of the inventory are the feed materials such as empty fruit bunches (EFB) and palm oil mill effluent (POME); and utilities which include electricity generated at palm oil mill and diesel used. Composting 2.0-2.5 t of EFB and 5.0-7.5 t of POME required diesel from 218.7 to $270.2 \mathrm{MJ}$ and electricity from 0 to $6.8 \mathrm{MJ}$. It is estimated that the composting emitted from 0.01 to $0.02 \mathrm{t} \mathrm{CO} 2 \mathrm{eq} / \mathrm{tcompost}$ mainly from diesel used to operate machineries. Composting saved $65 \%$ of time required for a complete degradation of POME when compared to ponding system, and $89 \%$ of time required for a complete degradation of EFB compared to mulching. In terms of land required, it required $36 \%$ less land as compared to ponding for POME and $99 \%$ less land as compared to mulching for EFB. Based on the case study, diesel was found to be the main contributor to the environmental impact. There is a potential of upgrading the process to be more economical and environmental friendly. Using electricity as the source of energy has a lower footprint for the composting process. Instead of using raw POME, studies had reported that using treated POME either from anaerobic ponding or digested tank can accelerate the composting process.
\end{abstract}

Keyword: Life cycle inventory; Commercial production; Compost; Palm oil mill effluent; Empty fruit bunches; Greenhouse gas emission 